\title{
Colorectal Cancer in Nineveh: Five Years Survival Rate
}

\author{
Moayad Aziz Alabdaly \\ Lecturer, PhD, Department of Family and Community Medicine, Medical College, University of Nineveh
}

\begin{abstract}
Overall, colorectal cancer ranks third in terms of incidence but second in terms of mortality, according to the latest GLOBOCAN worldwide estimation in 2018. The aim of this study is to show the survival rates of colorectal cancer patients in Nineveh province for the period 2010 - 2014, a retrospective cohort study, conducted among patients at the Mosul Cancer Registry center. Survival analysis was carried out using the actuarial method to construct the needed life tables. Chi-square test, was used to study the relationship between cancer occurrence and sex, age and stage. The result of this study indicates that the 5 year survival rate $(50.1 \%)$ with $95 \%$ confidence intervals $(0.4985-0.5035)$ in Mosul was between developed and developing countries. The survival of colorectal cancer in men $(50.0 \%)$ was significantly better than women (43.0\%), older patients $\geq 70$ years, had a poorer survival rate $(25.9 \%)$ compared to younger patients $<50$ years $(70.5 \%)$ and the survival rate by tumor stage was better in the localized stage $(75.4 \%)$ than regional and distant stages of $(63.6 \%$ and $11.7 \%)$ respectively.
\end{abstract}

Keywords: Colorectal cancer, 5-year survival rate, Mosul Cancer Registry center

\section{Introduction}

Over 1.8 million new colorectal cancer cases and 881,000 deaths are estimated to occur in $2018^{1}$. Colorectal cancer (CRC) is the third most common cancer in men and the second in women, according to the latest GLOBOCAN worldwide estimation in $2012^{1,2}$. About $55 \%$ of the cases are reported in the more developed countries. The highest rates were estimated to be in Australia/New Zealand: 44.8 and 32.2 per 100,000 in men and women, respectively, and the lowest in Western Africa $(4.5 \text { and } 3.8 \text { per } 100,000)^{2}$. Colorectal cancer is a major cause of morbidity and mortality throughout the world ${ }^{3}$. It accounts for over $9 \%$ of all cancer incidence 4,5 . It is the third most common cancer worldwide and the second most common cause of death ${ }^{1,4}$. It affects men and women almost equally ${ }^{3-6}$. Colorectal cancer is one of the ten leading cancers in Iraq, accounting for $4.8 \%$ of estimated cancer cases in males and $3.8 \%$ of estimated cancer cases in females ${ }^{7}$.

\section{Aim of The Study}

The aim of this study is to show the survival rates of CRC patients in Nineveh province for the period 2010 $-2014$.

\section{Objectives}

1. To describe the sociodemographic characteristics of the CRC patients.

2. To calculate the 5-year survival rate (5YSR), according to the age, sex and stage of the cancer.

\section{Materials and Method}

\section{Study Settings:}

This was a retrospective cohort study, conducted among patients at the Mosul Cancer Registry center (MCRC). This study protocol was approved by the local ethics committee of Medical Collage, University of Nineveh and also obtained from the directorate of health in Nineveh

\section{Study sample:}

The sample of the present study included all colon and rectum cancer patients registered at the Mosul cancer registry center in Nineveh in 2010 to 2014 of all ages and both sexes. A total of 460 cases of CRC, recorded were retrieved from the medical records of MCRC.

The cancer cases are registered with respect to patient number, age, sex, clinical stage and cancer coded according to the International Classification of Diseases 
$(\mathrm{ICD} 10)^{8,9}$. All the data are fitted on Can Reg 3 format and fed into the computerized database of the MCRC.

Staging is done according to the summary stage system $^{10,11}$. The cancer has become invasive and is categorized as local, regional, or distant based on the extent of spread ${ }^{12}$. Stage "unknown" has been recorded to include tumour morphologies for which the summary stage system is not strictly applicable and patients with cancer of an unknown stage or carcinoma in situ were excluded from the present study.

The criteria of the age groups chosen were those used for the international standard cancer patient population ${ }^{13}$. With age been categorized into three groups $(<50,50-69$ and $70+$ years).

The sex was examined as a potential confounding variable for CRC for presentation of some descriptive results.

\section{Survival Analysis}

Survival analysis was carried out using the actuarial method to construct the needed life tables ${ }^{14}$. Observed survival rate "OSR" is the probability of surviving from all causes of death in a group of cancer patients under study. Observed survival was measured from the date of diagnosis to the date of death or censoring, whichever occurred first ${ }^{14,15,16}$. Cancer patient survival was estimated as the cumulative probability (range 0 to 1) of survival up to a stated time after diagnosis ${ }^{17}$. This method has been used in this study to estimate the absolute survival probability ${ }^{18}$. In the present study, period analysis was used to derive 5-year survival estimates for 2010-2014 ${ }^{19,20}$.

\section{Statistical Analysis}

95\% confidence intervals and calculation of the standard error (s.e.) of the 5YSR obtained by the actuarial method uses the Greenwood's formula ${ }^{14,21}$. Chi-square test was used to study the relationship between variables and some results ${ }^{22}$.

Micro Soft Excel 2010 was used for statistical analysis.

\section{Results}

The total number of the CRC cases, according to age, sex and stage of extension are shown in Table 1 . The result is significant at $p \leq 0.05$, except for sex, the result is not significant and the chi-square statistic is 2.513 .

Table 1: The frequency distribution of the colorectal cancer cases, according to age, sex and stage of disease.

\begin{tabular}{|c|c|c|c|c|c|c|c|c|c|}
\hline \multirow{2}{*}{\multicolumn{2}{|c|}{$\begin{array}{l}\text { Colorectal Cancer Cases } \\
(\mathbf{4 6 0 )}\end{array}$}} & \multicolumn{5}{|c|}{ Date of Diagnosis } & \multirow{3}{*}{$\begin{array}{l}\text { Total } \\
154\end{array}$} & \multirow{2}{*}{$\%$} & \multirow{2}{*}{ p-value } \\
\hline & & 2010 & 2011 & 2012 & 2013 & 2014 & & & \\
\hline \multirow{3}{*}{$\begin{array}{l}\text { Age } \\
\text { group }\end{array}$} & $<50$ & 22 & 41 & 30 & 29 & 32 & & 33.5 & \multirow{3}{*}{$<0.00001$} \\
\hline & $50-69$ & 38 & 34 & 49 & 42 & 61 & 224 & 48.7 & \\
\hline & $\geq 70$ & 11 & 8 & 20 & 21 & 22 & 82 & 17.8 & \\
\hline \multirow{2}{*}{ Sex } & Female & 28 & 42 & 50 & 48 & 45 & 213 & 46.3 & \multirow{2}{*}{0.11291} \\
\hline & Male & 43 & 41 & 49 & 44 & 70 & 247 & 53.7 & \\
\hline \multirow{4}{*}{ Stage } & Local & 14 & 8 & 26 & 17 & 27 & 92 & 20.0 & \multirow{4}{*}{$<0.00001$} \\
\hline & Regional & 30 & 42 & 34 & 25 & 51 & 182 & 39.6 & \\
\hline & Distant & 26 & 21 & 27 & 27 & 28 & 129 & 28.0 & \\
\hline & Unknown & 1 & 12 & 12 & 23 & 9 & 57 & 12.4 & \\
\hline
\end{tabular}

To CRC death, about half of people (50.3\%) die, is of 55-69 year of age, as shown in Table 2, 
Table 2: The frequency distribution of the colorectal cancer deaths, according to age, sex and stage of disease.

\begin{tabular}{|c|c|c|c|c|c|c|c|c|}
\hline \multirow{2}{*}{\multicolumn{2}{|c|}{ Colorectal Cancer Deaths (163) }} & \multicolumn{5}{|c|}{ Date of Diagnosis } & \multirow{3}{*}{$\begin{array}{c}\text { Total } \\
36\end{array}$} & \multirow{3}{*}{\begin{tabular}{|c|}
$\%$ \\
22.1
\end{tabular}} \\
\hline & & \multirow{2}{*}{$\begin{array}{c}2010 \\
0\end{array}$} & \multirow{2}{*}{$\begin{array}{c}2011 \\
3\end{array}$} & \multirow{2}{*}{$\begin{array}{c}2012 \\
11\end{array}$} & \multirow{2}{*}{$\begin{array}{c}2013 \\
9\end{array}$} & \multirow{2}{*}{$\begin{array}{c}2014 \\
13\end{array}$} & & \\
\hline \multirow{3}{*}{ Age group } & $<50$ & & & & & & & \\
\hline & $50-69$ & 3 & 7 & 17 & 21 & 34 & 82 & 50.3 \\
\hline & $\geq 70$ & 6 & 2 & 6 & 12 & 19 & 45 & 27.6 \\
\hline \multirow{2}{*}{ Sex } & Female & 2 & 6 & 15 & 17 & 36 & 76 & 46.6 \\
\hline & Male & 7 & 6 & 19 & 25 & 30 & 87 & 53.4 \\
\hline \multirow{4}{*}{ Stage } & Local & 0 & 0 & 3 & 9 & 6 & 18 & 11.0 \\
\hline & Regional & 2 & 5 & 11 & 16 & 17 & 51 & 31.3 \\
\hline & Distant & 7 & 7 & 16 & 15 & 35 & 80 & 49.1 \\
\hline & Unknown & 0 & 0 & 4 & 2 & 8 & 14 & 8.6 \\
\hline
\end{tabular}

Table 3, shows the CRC survival rate declined from $70.5 \%$ in the $\leq 50$ age group to $25.9 \%$ among those aged $\geq 70$ years. There was an greater difference in survival rates between female and male, which were $43.0 \%$ and $50.0 \%$, respectively and between stages.

Table 3: The 5- year observed survival rate of the colorectal cancer cases, according to overall, age group, sex and stages for the period from (2010-2014)

\begin{tabular}{|c|c|c|c|}
\hline \multicolumn{2}{|c|}{ Colorectal Cancer } & \multirow{2}{*}{$\begin{array}{l}\text { OSR } \\
0.501\end{array}$} & \multirow{2}{*}{$\begin{array}{l}\mathbf{9 5 \%} \text { CI } \\
0.4985-0.5035\end{array}$} \\
\hline & Overall & & \\
\hline \multirow{3}{*}{ Age Group } & $<50$ & 0.705 & $0.7003-0.7100$ \\
\hline & $50-69$ & 0.518 & $0.5127-0.5240$ \\
\hline & $\geq 70$ & 0.259 & $0.2152-0.3032$ \\
\hline \multirow{2}{*}{ Sex } & Female & 0.430 & $0.4251-0.4343$ \\
\hline & Male & 0.500 & $0.4954-0.5045$ \\
\hline \multirow{3}{*}{ Stage } & Local & 0.754 & $0.7469-0.7603$ \\
\hline & Regional & 0.636 & $0.6305-0.6411$ \\
\hline & Distant & 0.117 & $0.0975-0.1363$ \\
\hline
\end{tabular}




\section{Discussion}

Previous studies in other countries have reported variable CRC survival rates.

In Asia, the highest survival rates were found in China $(68.0 \%)^{23}$, the lowest rate was in India (33.6\%) and Malaysia (34.3\%) ${ }^{24,25}$. This study showed that the overall 5YSR for patients with CRC was $50.1 \%$. Various studies from Iran have reported 5YSR of CRC of 47\%, $41 \%$ and $61 \%$ respectively ${ }^{26-28}$. In Saudi Arabia, the overall 5YSR of the CRC was $44.6 \%{ }^{29}$. The disparities in CRC survival between Japanese, Mediterranean countries could also be attributed to many factors, together with variations in socioeconomic standing, stage at identification, treatment, medical practitioner characteristics, and hospital factors. In Japan in 2005, the 5YSR was reported at $61.4 \%{ }^{30}$. Also, studies in Germany, USA, England, France, and Italy were reported the 5 YSR $65 \%, 65 \%, 52.7 \%, 60.3 \%$ and $59.3 \%$ respectively ${ }^{31-34}$. The 5YSR of patients with CRC in our city is lower than the developed regions. Therefore, we conclude that the survival rate of patients with CRC in Mosul is between developed and developing countries, like other patients in the world depend on various factors such as demographics, pathologic and tumor characteristics, geographical distribution and gene mutation or have a family history of ${ }^{35,36}$.

In this study, there is no significant difference in the occurrence of CRC between females and males $(p$-value $=0.11291)$, but differences in survival rates were reported, $43.0 \%$ and $50.0 \%$, for females and males, respectively. Yet, other studies had reported a lower 5YSR in females ${ }^{2,37}$. The absence of gender differences in survival rates was reported in some of the previous studies ${ }^{23,25}$. In a study in Germany and Cuba, the 5YSR in women was better than men that were not similar to the result of our study ${ }^{38,39}$. The reason for better survival in men than women in this study may be due to a higher participation rate in men compared with women for screening programs like fecal occult blood test and colonoscopy ${ }^{40}$.

This study showed that the hazard of death increased significantly with increased age being the highest in the age of $\geq 70$ years. This result was reported in other studies ${ }^{27}$ that showed that older patients had a poorer survival rate compared to younger patients. However, other studies ${ }^{26,41}$ reported no difference in survival according to age. The contradictory results of previous studies on age may be due to the inclusion of patients from single referral centers and poor adjustment for the effect of possible confounds.

One of the most important factors that influence the survival of patients with CRC was the stage of diagnosis. Which were $75.4 \%, 63.6 \%$ and $11.7 \%$, for local, regional and distant stages respectively. This finding is consistent with findings of other studies; in the USA, 5YSR is $90 \%$; survival in local stage, declines to $71 \%$ and $14 \%$ with regional and distant stages, respectively ${ }^{34}$, also in European countries, localized CRC reached levels close to $90 \%$ and $15 \%$ in the case of distant stage ${ }^{38}$, while in Saudi Arabia, $63.3 \%$ for localized disease, $50.2 \%$ for those with regional disease, and $14.7 \%$ for patients with distant stage ${ }^{29}$. But the most important factor for our CRC patient is that the disease diagnosed at an advanced stage $^{42}$. So this significant difference in 5YSR may be due to, poorly established screening program like the fecal occult blood test, sigmoidoscopy and colonoscopy and limited accessibility in developing region ${ }^{43}$.

\section{Conclusions}

In conclusion, the result of this study indicates that the 5YSR of patients with CRC in Mosul was between developed and developing countries. The survival of CRC in men was significantly better than women, older patients had a poorer survival rate compared to younger patients and the survival rate by tumor stage was better in the localized stage than other stages of CRC.

Conflict of Interest: no conflict of interest.

\section{Source of Funding: self}

Ethical Clearance: From Ethical Committee, Medical College, University of Nineveh

\section{References}

1. Bray F, Ferlay J, Soerjomataram I, Siegel RL, Torre LA, Jemal A. Global cancer statistics 2018: GLOBOCAN estimates of incidence and mortality worldwide for 36 cancers in 185 countries. CA: a cancer journal for clinicians. 2018 Nov; 68 (6): 394-424.

2. Ferlay J, Soerjmataram I, Ervik M, Dikshit R, Eser S, Mathers C, et al. GLOBOCAN 2012 cancer incidence and mortality worldwide: IARC CancerBase No. 11 [Internet]. Lyon, France: International Agency for Research on Cancer; 2013. 
3. World Health Organization. Cancer Incidence in Five Continents. Lyon: The World Health Organization and The International Agency for Research on Cancer; 2002

4. World Cancer Research Fund and American Institute for Cancer Research. Food, Nutrition, Physical Activity, and the Prevention of Cancer: A Global Perspective. Washington, DC: American Institute for Cancer Research; 2007

5. Boyle P, Ferlay J. Mortality and survival in breast and colorectal cancer. Nat Clin Pract Oncol 2005; 2 (9):424-425

6. Parkin D, Bray F, Ferlay J. Global cancer statistics, 2002. CA Cancer J Clin 2006;55:74-108

7. Iraqi Ministry of Health. Department of vital statistics 2008 report

8. Coleman MP, Forman D, et al: Cancer survival in Australia, Canada, Denmark, Norway, Sweden, and the UK, 1995-2007 (the International Cancer Benchmarking Partnership): an analysis of population-based cancer registry data. Lancet 2011, 377 (9760): 127-138.

9. World Health Organization. International statistical classification of diseases and related health problems. World Health Organization; 2004.200.

10. Young J Jr, Roffers S, Ries L, Fritz A, Hurlbut A: SEER Summary Staging Manual - 2000: Codes and Coding Instructions. Bethesda, MD: National Cancer Institute; 2001.

11. Greene FL, Page DL, Fleming ID, Fritz AG, Balch CM, Haller DG, et al. AJCC cancer staging manual. 6th ed. New York: Springer; 2002.

12. International agency for research on cancer. World cancer fact sheet UK 2012. World Health Organization. www. Cancer researchuk.org, 2014.

13. Corazziari I, Quinn M, Capocaccia R. Standard cancer patient population for age standardizing survival ratios. EUR $J$ Cancer 2004; 40: $2307-$ 2316.

14. Paul W. D And Timo H. Estimating Cancer Patient Survival, Population-Based Cancer Survival Analysis 2003; 21-33.

15. Chun-Ju Chiang, e tal. Incidence and survival of adult cancer patients in Taiwan, 2002-2012: Journal of the Formosan Medical Association 2016; 115: 1076-1088.

16. Gordis L. Epidemiology, Saunders Elsevier.
Philadelphia, Pa, USA,. 2008.

17. Capocaccia R, Gatta G, Roazzi P, Carrani E, Santaquilani M, De Angelis R, Tavilla A. The EUROCARE-3 database: methodology of data collection, standardization, quality control and statistical analysis. Annals of Oncology. 2003 Dec 1;14 (90005): 14-27.

18. Swaminathan R, Brenner H. Statistical methods for cancer survival analysis. IARC Sci Publ. 2011;162:7-13.

19. Brenner H, Gefeller O. An alternative approach to monitoring cancer patient survival. Cancer 1996; 78: 2004-2010.

20. Brenner H, Gefeller O, Hakulinen T: 2004. Period analysis for _up-to-date,, cancer survival data: theory, empirical evaluation, computational realization and applications. EUR J Cancer 2004, 40:326-35.

21. Ryabko BY, Stognienko VS, Shokin YI. A new test for randomness and its application to some cryptographic problems. Journal of statistical planning and inference. $2004 \mathrm{Jul}$ 1;123 (2): 365-76.

22. Yu et al. BMC Cancer 2012; 12: 460

23. 23- Yuan Y, Li MD, Hu HG, Dong CX, Chen JQ, Li XF, Li JJ, Shen H. Prognostic and survival analysis of 837 Chinese colorectal cancer patients. World Journal of Gastroenterology: WJG. 2013 May 7;19(17):2650.

24. Yeole BB, Sunny L, Swaminathan R, Sankaranarayanan R, Parkin DM. Populationbased survival from colorectal cancer in Mumbai,(Bombay) India. European Journal of Cancer. 2001 Jul 1;37(11):1402-8.

25. Ghazali AK, Musa KI, Naing NN, Mahmood Z. Prognostic factors in patients with colorectal cancer at Hospital Universiti Sains Malaysia. Asian J Surg 2010; 33: 127-133

26. Moghimi-Dehkordi B, Safaee A, Zali MR. Prognostic factors in 1,138 Iranian colorectal cancer patients. Int J Colorectal Dis 2008; 23: 683688

27. Moradi A, Khayamzadeh M, Guya MM, Mirzaei HR, Salmanian R, Rakhsha A, Akbari ME. Survival of colorectal cancer in Iran. Asian Pac J Cancer Prev 2009; 10: 583-586

28. Mehrabani D, Almasi-Hashiani A, Moshfeghi K, Khedmati E. Survival rate and its predictors in 
colorectal cancer patients, Southern Iran. Middle East J Sci Res. 2012;12(8):1072-7.

29. Al-Ahwal MS, Shafik YH, Al-Ahwal HM. First national survival data for colorectal cancer among Saudis between 1994 and 2004: what's next?. BMC Public Health. 2013 Dec;13(1):73.

30. Shiono S, Ishii G, Nagai K, Yoshida J, Nishimura M, Murata Y, Tsuta K, Nishiwaki Y, Kodama T, Ochiai A. Histopathologic prognostic factors in resected colorectal, lung metastases. The Annals of thoracic surgery. 2005 Jan 1;79 (1): 278-82.

31. Majek O, Gondos A, Jansen L, et al. GEKID Cancer Survival Working Group Survival from colorectal cancer in Germany in the early 21 st century. Br J Cancer. 2012;106:1875-1880

32. N. Howlader, A. M. Noone, M. Krapcho et al., Eds., SEER Cancer Statistics Review, 1975-2013, National Cancer Institute, Bethesda, Md, USA, 2016.

33. Brenner H, Bouvier AM, Foschi R, et al., Progress in colorectal cancer survival in Europe from the late 1980 s to the early 21 st century: the EUROCARE study. Int J Cancer, 2012;131, 1649-58.

34. American Cancer Society. Colorectal Cancer Facts \& Figures 2017-2019; American Cancer Society: Atlanta, GA, USA, 2017; Available online: https:// www.cancer.org/content/dam/cancer-org/research/ cancer-facts-and-statistics/ colorectal-cancerfacts-and-figures/colorectal-cancer-facts-andfigures-2017-2019. pdf (accessed on 23 Aug. 2019)

35. Dolatkhah R, Somi MH, Bonyadi MJ, Asvadi Kermani I, Farassati F, Dastgiri S. Colorectal cancer in Iran: molecular epidemiology and screening strategies. Journal of cancer epidemiology. 2015;110.
36. Rafiemanesh H, Pakzad R, Abedi M, Kor Y, Moludi J, Towhidi F, Makhsosi BR, Salehiniya H. Colorectal cancer in Iran: Epidemiology and morphology trends. EXCLI journal. 2016;15:738.

37. Hansen IO, Jess P. Possible better long-term survival in left versus right-sided colon cancer-a systematic review. Dan Med J. 2012 Jun 1;59 (6): A4444.

38. Majek O, Gondos A, Jansen L, et al. Sex differences in colorectal cancer survival: population-based analysis of 164,996 colorectal cancer patients in Germany. PLoS One, 2013; 8, e68077.

39. Garrote L, Alvarez Y, Babie P, et al., Cancer survival in Cuba, 1994-1995. IARC Sci Publ, 2011; $162,89-95$.

40. Meissner HI, Breen N, Klabunde CN, Vernon SW. Patterns of colorectal cancer screening uptake among men and women in the United States. Cancer Epidemiol Biomarkers Prev 2006;15:389-94.

41. Wang Z, Zhou ZX, Liang JW, Bai XF, Bi JJ. Prognostic factors of colorectal cancer patients with synchronous liver metastasis treated with simultaneous liver and colorectal resection. Zhonghua zhong liu za zhi [Chinese journal of oncology]. 2008 May;30(5):372-5.

42. Dolatkhah R, Somi MH, Bonyadi MJ, Asvadi Kermani I, Farassati F, Dastgiri S. Colorectal cancer in Iran: molecular epidemiology and screening strategies. Journal of cancer epidemiology. 2015;2015.

43. Sankaranarayanan R, Swaminathan R, Jayant K, Brenner $H$. An overview of cancer survival in Africa, Asia, the Caribbean and Central America: the case for investment in cancer health services. IARC Sci Publ. 2011;162:257-91. 